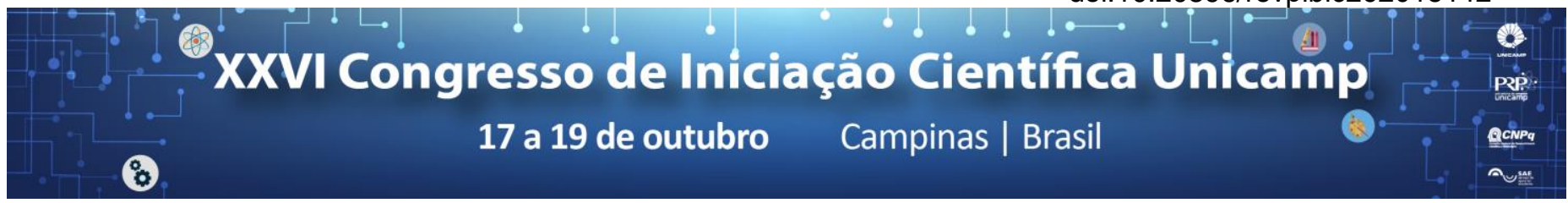

\title{
Sistema de rastreamento de bagagens em aeroportos brasileiros usando identificação por radiofrequência (RFID).
}

\section{Ana Sofia B. Baldo*, Leandro R. Ximenes.}

\section{Resumo}

O aumento do número de extravios e perdas de bagagens em aeroportos se tornou um aspecto muito importante para as operadoras do sistema aeroportuário, uma vez que isso implica em indenizações devidas aos passageiros prejudicados. Neste projeto foi desenvolvido um sistema de rastreamento de bagagens, em que etiquetas passivas RFID são colocadas nas bagagens, identificando informações sobre o passageiro e características específicas do item despachado. O sistema é constituído por uma leitor RFID baseado na plataforma Arduino, em um programa/servidor acessível pela operadora da companhia aérea e um aplicativo de smartphone para uso pelo passageiro.

\section{Palavras-chave:}

Identificação por radiofrequência (RFID), rastreamento, transporte aéreo.

\section{Introdução}

O rastreamento por radiofrequência (RFID) é baseado na a troca constante de dados entre etiquetas (tags) e leitores RFID, e desse modo permite identificar com precisão a localização de uma carga em tempo real. Para este projeto, foi feito um estudo da tecnologia RFID, uma análise dos requisitos padronizados para sistemas de rastreamento e então foi desenvolvido um sistema de gerenciamento para os responsáveis pela logística aérea e um aplicativo móvel de rastreamento em tempo real disponível ao passageiro. [1,2]

\section{Resultados e Discussão}

O estudo realizado para averiguar os requisitos de sistemas de rastreamento de bagagem buscou enfatizar as etapas do processo logístico das bagagens nos aeroportos brasileiros e os requisitos proferidos pela Resolução 753 da IATA (Associação Internacional de Transporte Aéreo). Para iniciar a prototipação do sistema, foi executado um estudo de caso a partir do uso do DER (Diagrama de Entidade e Relacionamento), de forma que fosse possível identificar as participações dos aeroportos, dos passageiros e das companhias aéreas.

As simulações e os testes do fluxo de dados do hardware do sistema foram feitos utilizando a placa de prototipação Arduino UNO conectada ao módulo leitor RFID MFRC522, que opera na frequência de $13,56 \mathrm{MHz}$. Logo, para a transmissão de dados em tempo real do rastreamento, foi necessário a interconexão dos dados do sistema, de forma que houvesse atualização instantânea entre o hardware, o banco de dados e as aplicações desktop e móvel. [3]

No desenvolvimento das aplicações desktop (para uso pelas operadoras) e móvel (para uso pelos passageiros), foram feitas pesquisas e análises comparativas, de acordo com os requisitos do sistema. E deste modo, foram escolhidas as seguintes plataformas de ambiente de programação: a IDE Eclipse para o desenvolvimento da aplicação desktop, o Android Studio para o desenvolvimento da aplicação móvel, ambas com uso da linguagem de programação Java, e para a modelagem de dados em SQL o software PostgreSQL.

A conexão do computador pessoal (PC), onde era rodada a aplicação desktop, com a placa do Arduino (atrelada ao leitor RFID), é vista na Figura 1. As telas das aplicações desenvolvidas são mostradas na Figura 2.

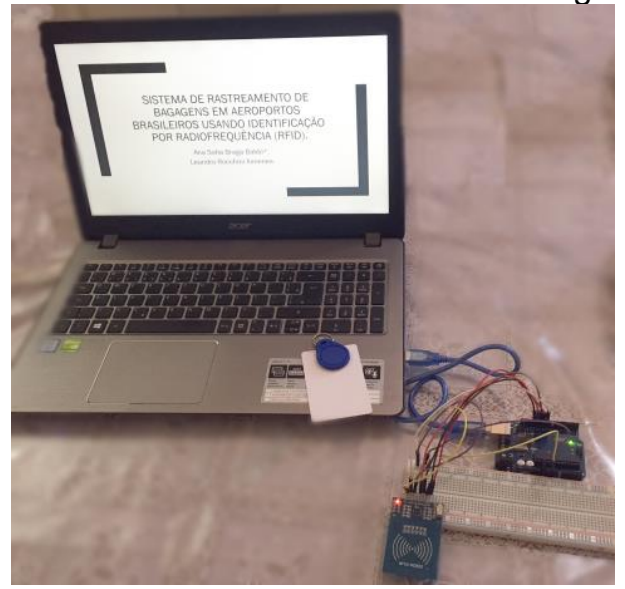

Figura 1: PC com placa Arduino e leitor RFID
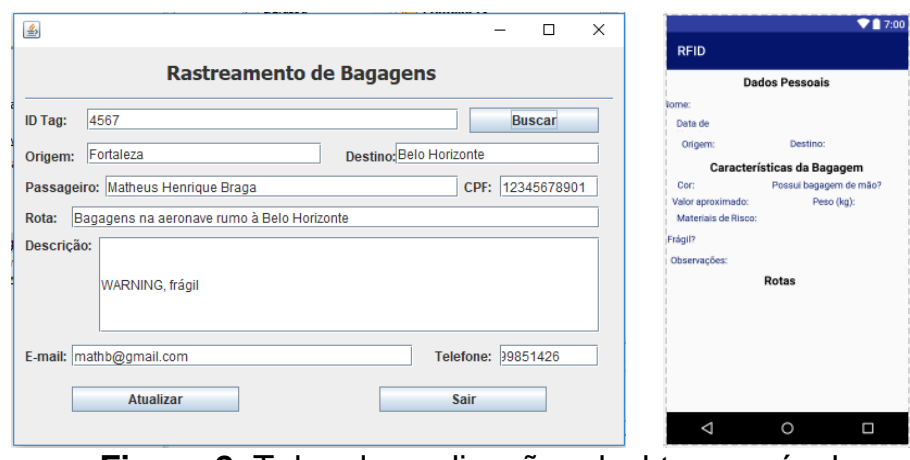

Figura 2. Telas das aplicações desktop e móvel.

\section{Conclusões}

Com os estudos e as análises dos principais conceitos de RFID e dos requisitos necessários em um sistema de rastreamento de bagagens, foi possível realizar a prototipação desse sistema, possibilitando 0 desenvolvimento das aplicações (desktop e móvel) de um sistema de rastreamento de baixo custo.

\footnotetext{
SITA, The Baggage Report, 2016.

2 A. Thomas. Statistics of Lost Luggage and How Airline Companies Are Addressing Them, 2016

3 R. S. G Villar. Implementando RFID na Cadeia de Negócios: Tecnologia a Serviço da Excelência. 2. ed. Brasil: Edipucrs, 2012. 238 p
} 